\title{
Simulating the impact of extreme heat and frost events on wheat production: the first steps
}

\author{
$\underline{\text { K.M. Barlow }}^{\text {a }}$, B.P. Christy ${ }^{\text {a }}$, G.J. O'Leary ${ }^{\text {b }}$, P.A. Riffkin ${ }^{\text {c }}$, and J.G. Nuttall ${ }^{\text {b }}$ \\ ${ }^{a}$ Future Farming Systems Research (FFSR), Department of Environment and Primary Industries (DEPI), \\ 124 Chiltern Valley Road, Rutherglen, Victoria 3685 AUSTRALIA. \\ ${ }^{b}$ FFSR, DEPI, 110 Natimuk Road, Horsham, Victoria 3400 AUSTRALIA. \\ ${ }^{c}$ FFSR, DEPI, Mt Napier Road, Hamilton, Victoria 3300 AUSTRALIA. \\ Email: Kirsten.Barlow@depi.vic.gov.au
}

\begin{abstract}
In Australia, wheat production occurs on over 13 million hectares, producing on average 19 million tonnes of wheat per year. Extreme weather events, such as frost and heat shock (short period of very high temperatures $\left(>35^{\circ} \mathrm{C}\right)$ ), can reduce wheat yields and represent a substantial management challenge. Damage due to frost and heat shock is greatest at ear emergence and around anthesis causing significant reductions in grain number and yield potential. Heat shock can also significantly reduce grain weight during the grain fill period when the risk of heat is greatest.

Paddock-based crop models currently used to simulate crop production do not adequately account for the impact of extreme weather events such as frost and heat shock on yield components. While it is feasible to construct crop modules which capture this impact by extreme short term weather events, we felt it was important to quantify the frequency and spatial extent of the problem. This was important in determining whether the frequency and extent of potential grain losses from extreme weather events warranted the inclusion of added parameter input complexity within crop models. By taking into account the interactions between climate and crop phenology we were able to categorise areas as frequently affected by either frost or heat shock, those areas affected by both heat and frost and finally those areas which were rarely affected by either. Strategies to reduce the risks of extreme events will potentially be different for each of these regions.
\end{abstract}

This paper investigates the spatial extent of where there is potential for improvements to the grains industry by having crop models which account for extreme heat and frost impacts linked to the key phenological crop stages. By incorporating phenological crop development, initiated by the autumn-break our analysis has established the actual frequency of overlap between extreme events and key phenological stages each year. This is important in determining the value of developing heat and frost modules to incorporate into crop models. To quantify the risk frequency of extreme heat and frost events across southern Australia's wheat growing regions the Catchment Analysis Tool (CAT, DEPI Victoria) was used. The study area (ca. 68 million hectares) incorporated agricultural land within the $200-1000 \mathrm{~mm}$ annual rainfall region and was significantly larger than the actual area sown to wheat annually. Two key periods were considered (a) a two week period centered on anthesis (50\% of crop flowering) and (b) grain fill, for mid-season wheat variety using 50 years historical climate data.

Based on our assumption of sowing at the autumn break, the occurrence of frost around anthesis and extreme heat during the grain fill period were important both in terms of frequency of occurrence and spatial area affected. Across the study region approximately $27 \%$ (ca. 18.5 million hectares) had a greater than 1:3 chance of both frost and extreme heat occurring at key crop phenological times, while $29 \%$ of the study area was generally affected by heat only during grain fill and $32 \%$ was generally affect by frost only. Additionally $12 \%$ (ca. 8 million hectares) had a less than 1:3 frequency of both frost and extreme heat occurring at key crop phenological times.

Keywords: CAT, phenology, heat waves, cropping 
Barlow et al., Simulating the impact of extreme heat and frost events on wheat production: the first steps.

\section{INTRODUCTION}

In Australia, wheat production occurs on over 13 million hectares, producing 19 million tonnes of wheat per year (based on a five year average to 2010/11: ABARE, 2012). Crop production across Australia is being increasingly impacted by climate as the average annual daily mean temperatures have increased progressively since the middle of the 20th Century against a backdrop of natural year to year variability (CSIRO and Bureau of Meteorology, 2012). The key challenge for crop production is the change in climate extremes, both the increased frequency of very hot $\left(>40^{\circ} \mathrm{C}\right)$ daytime temperatures since the 1990's (CSIRO and Bureau of Meteorology, 2012) and the increased incidence of frost across the Australian grain belt between 1960 and 2011 (GRDC Groundcover November 2012). Extreme weather events, such as frost and heat shock (short period of very high temperatures $\left(>35^{\circ} \mathrm{C}\right)$ ), are reducing crop production and represent a substantial challenge to the Australian Grain Industry.

Frost damage is an economic problem globally. In Australia economic losses due to frost damage are estimated to be at least $\$ 120$ million per year. Frost around flowering and ear emergence has been identified as a period of significant risk for wheat and other grain crops. Frost during early flowering and ear emergence can result in partial or complete sterility of florets and whole spikelets and therefore reduced grain number and yield (Al-Issawi et al., 2012; Marcellos and Single, 1984).

Heat damage from extreme heat events $\left(>35^{\circ} \mathrm{C}\right)$ contribute to yield loss (e.g. 17-35\%; Alexander et al., 2010; Stone and Nicolas, 1995; Talukder et al., 2010) which translate to notable economic losses. High temperature stress at anthesis impacts wheat yield by reducing grain number at anthesis and kernel size in the post anthesis phase, with Ferris et al. (1998) finding that fertilisation and grain set were most sensitive to high temperature at $50 \%$ anthesis. In addition, heat shock during grain fill can trigger premature senescence, decreased leaf chlorophyll, inhibit kernel development and alter starch and protein composition (Pradhan et al., 2012; Wardlaw and Wrigley, 1994).

In Australia, growers have historically managed potential loss from frost by sowing late, thus ensuring crops flower after the frost risk window has passed. However, there is a small and variable window between reduced frost risk and limiting the risk of extreme heat events later in the growing season. Delayed planting to reduce the risk of frost can result in a known opportunity cost up to 2-3 fold higher than direct losses from frost (Fuller et al., 2007) due to crops facing above-optimum temperatures during grain fill. Crop growth models have been used to help farmers understand and manage these competing aims so that they can balance the risks and maximise the growing season to optimise production. However, of five popular crop models (CERES-Wheat, EPIC, APSIM, CropSyst and CAT) used in Australia, none adequately account for heat shock and frost impacts on yield.

Crop models need to adequately account for the effect of extreme weather events such as frost and heat shock, if they are to assist in boosting crop production through improved management options and enhanced identification of desired genetic traits. While there has been a lot of research into heat and frost impacts on crops and yields the majority of commonly used crop models don't have extreme heat and frost modules, although these impacts are in part accounted for through other stress factors. More specifically the models don't incorporate a step reduction in yield components such as grain number in response to a single frost or extreme heat event consistent with the available research data. This suggests that there would be value in the development of crop model components/algorithms to describe these impacts. However, substantial work is required to develop and test new crop component models.

This paper describes an important first step in this process, which is developing an understanding of the frequency and spatial extent in which these model components could be utilised across the cropping regions. For example, if a cropping region is impacted infrequently by frost (eg. once or twice every 50 years) then parameterizing a frost module in that grain region would have limited value in informing the management and yield potential of cropping systems. In contrast, if a frost model had the potential to influence crop yield because there is a high frequency of frosts around anthesis within a particular cropping region, then the development and testing of a frost algorithm would be warranted. The same logic applies to the development of heat shock algorithms.

\subsection{Objectives}

The objective of this paper was to quantify the risk of extreme heat and frost events occurring and being triggered within a crop model across southern Australia’s wheat growing regions. 
Barlow et al., Simulating the impact of extreme heat and frost events on wheat production: the first steps.

\section{METHODOLOGY}

The Catchment Analysis Tool (CAT Version 8.4.5) was selected to investigate the frequency with which frost and extreme heat events coincided with anthesis and grain fill periods across Australia, due to its ability to undertake spatial analysis. The CAT crop model represents biomass accumulation based on extensively used contemporary models (DPI, 2009; Littleboy et al., 1992; Williams et al., 1989) and has high utility in spatial analyses across landscapes (Weeks et al., 2008). It includes modules for plant phenology, crop growth and yield, together with dynamics of water and nitrogen in the crop and soil. CAT first simulates phenological progress, above-ground biomass accumulation and then partitioning to grain. Phenological development is driven by temperature and photoperiod. All the major field crops that have been successfully simulated with CAT have previously defined default parameters, including early, mid and late season wheat varieties (DPI, 2009; O’Leary et al., 2011).

The CAT model was applied across southern Australia over a 50 year period (Figure 1). Model simulation was conducted on $1 \mathrm{~km}^{2}$ grid cells of agricultural land within the 200-1000 mm annual rainfall region (ca. 68 million hectares) as shown in Figure 1. For each year and grid cell within this region, the CAT model planted wheat at the autumn break (defined by $25 \mathrm{~mm}$ rain in 10 days) for a mid-season wheat cultivar. In each year the number of days in which the minimum temperature was $<2^{\circ} \mathrm{C}$ and the maximum temperature was $>35^{\circ} \mathrm{C}$ during a 2 week period centred around anthesis $(50 \%$ flowering) and the grainfill period (from anthesis to harvest) was recorded.

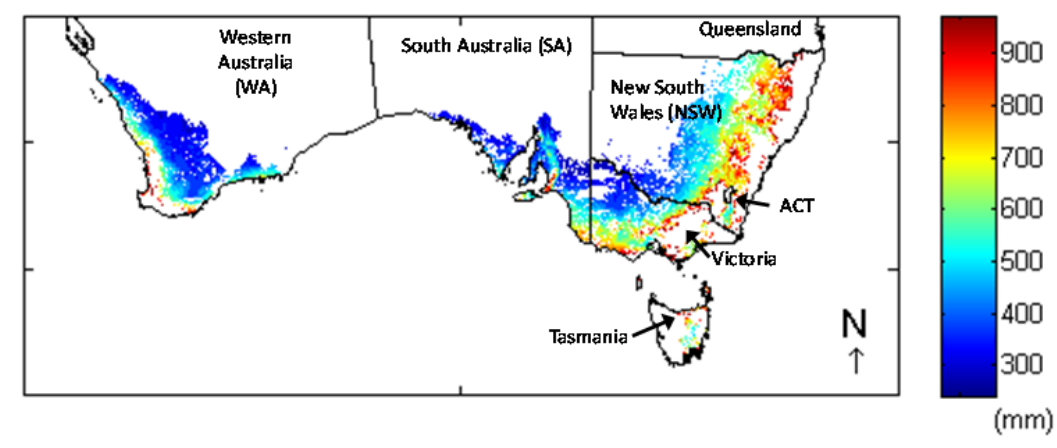

Figure 1. The study region in southern Australia showing the range in mean annual rainfall.

As the analysis was to

investigate the overlap of phenological stage with extreme temperatures, rather than actual production, crop death in response to water and nutrient stresses was deactivated to allow a crop to continue its phenological development, although no crop yield was recorded for that crop in that year.

\section{RESULTS}

Based on an autumn break rule of $25 \mathrm{~mm}$ rain in a 10 day period, the sowing date across southern Australia ranged from April through to July. The average sowing date (for 50 years in each grid cell) across the study area ranged from the 3 April through to the 6 July (Figure 2). At each point in the landscape this sowing date is the average of 50 autumn breaks. The overall average autumn break for the study area was 12 May with the drier areas of the study region generally representing the later autumn breaks and the high rainfall zone the earlier ones.
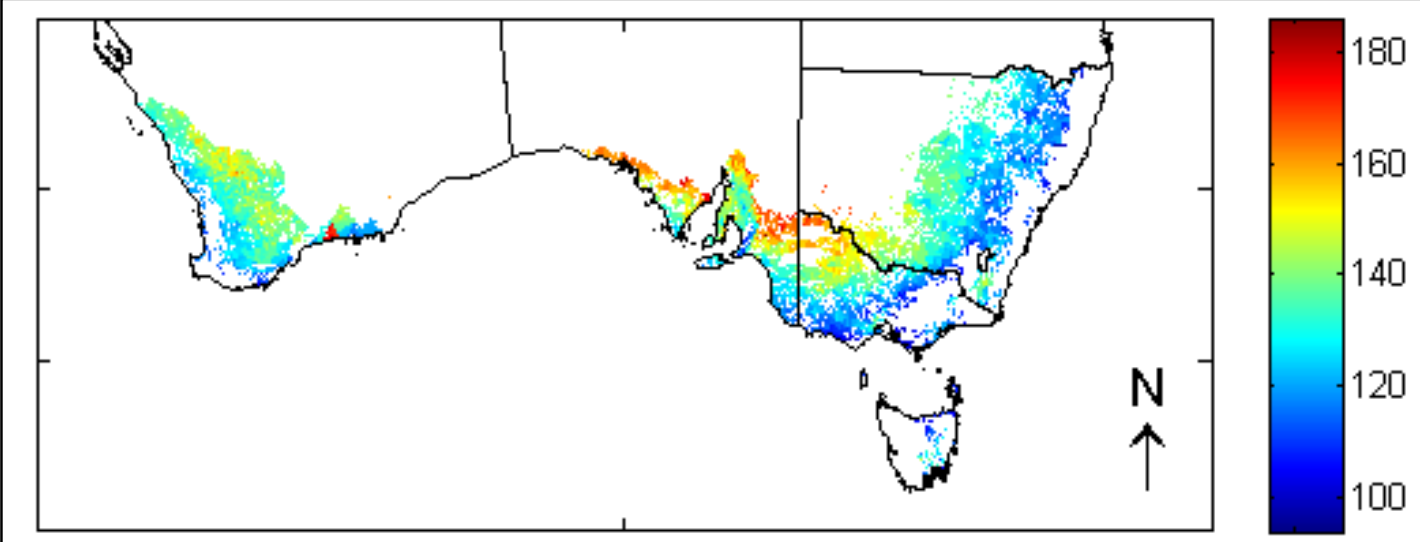

Figure 2. Average sowing date (day of year) across the study region in southern Australia based on a $25 \mathrm{~mm}$ rain in 10 days autumn break. 
Barlow et al., Simulating the impact of extreme heat and frost events on wheat production: the first steps.

The average time between sowing and anthesis (based on 50 years in each grid cell) ranged from 60 to 240 days, with the average across the study region of 130 days. This resulted in a spread of average anthesis date from mid-July to end of December across the study area and an average anthesis date of mid-September.

\subsection{Frost around anthesis}

Wheat crops are most sensitive to frost damage during reproductive growth, particularly around anthesis when a reduction in fertility and yield can result from a single frost event.

The common method to determine if a frost event has occurred uses a standard criterion of $2.2^{\circ} \mathrm{C}$ (measured in a Stevenson Screen at $1.2 \mathrm{~m}$ above ground level). This temperature is known to cause frost damage in flowering crops, as temperatures at canopy height are invariably much lower than at the Stevenson Screen (Rebbeck and Knell, 2007).

As shown in Figure 3 there was a large variation in the occurrence of frost across southern Australia. On average frost coincided with anthesis 18 out of the 50 years, with the number of years notably greater in NSW where frost coincided an average of 25 years in 50 (Figure 3a). Across the study region, there was an average of 2 frost days in the years where frost coincided with anthesis, the number of frost days a year increased as from Victoria to the Queensland border (Figure 3b).

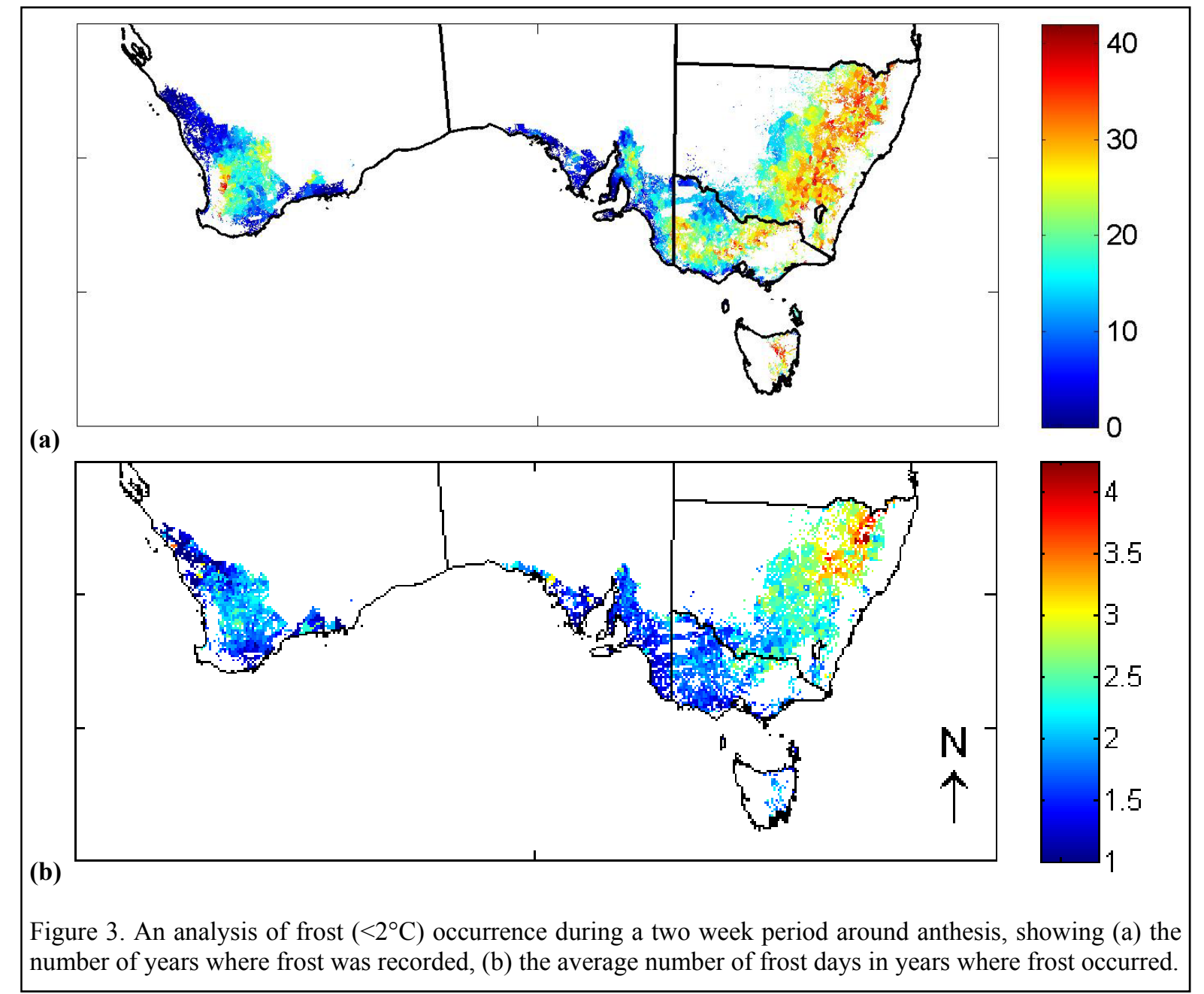

Based on the decision of planting at the autumn break, the results suggest that the occurrence of frost during the anthesis period was considerable (occurring approximately 2 in 5 years) and a frost component would be implemented frequently during a 50 year model run across the study region. However, it is important to note that planting was based purely on rainfall and did not consider other management factors such as antecedent soil water or frost avoidance strategies such as delayed planting. 
Barlow et al., Simulating the impact of extreme heat and frost events on wheat production: the first steps.

\subsection{Heat around anthesis}

Short periods of extreme heat around anthesis can result in sterility and therefore reduced yields in wheat crops. Based on our assumption of planting time, extreme heat days $\left(>35^{\circ} \mathrm{C}\right)$ occurred less frequently around anthesis than frost days. On average there were only 2.3 years out of 50 when an extreme heat day coincided with the anthesis period. This result suggests that whilst extreme heat during anthesis may occur, the frequency with which it occurs would make this a lower priority from a modelling and management perspective than either frost or heat during grain fill. However, this may become a more important priority under future climate scenarios.

\subsection{Heat during grain fill}

Extreme heat during grain fill, particularly temperatures greater than $35^{\circ} \mathrm{C}$ which can result in heat shock, result in reduced grain set and grain size. The frequency of extreme heat events during grain fill averaged 19 years out of 50 across the study region. The frequency increased with distance inland to the more arid regions of the study area, with the greatest frequency in northern Victoria and South Australia (Figure 4a). Similarly the number of extreme heat days occurring in a year where extreme heat was recorded increased with distance from the coast. On average there were three heat days recorded in a year when at least one occurred (Figure 4b).

(a)
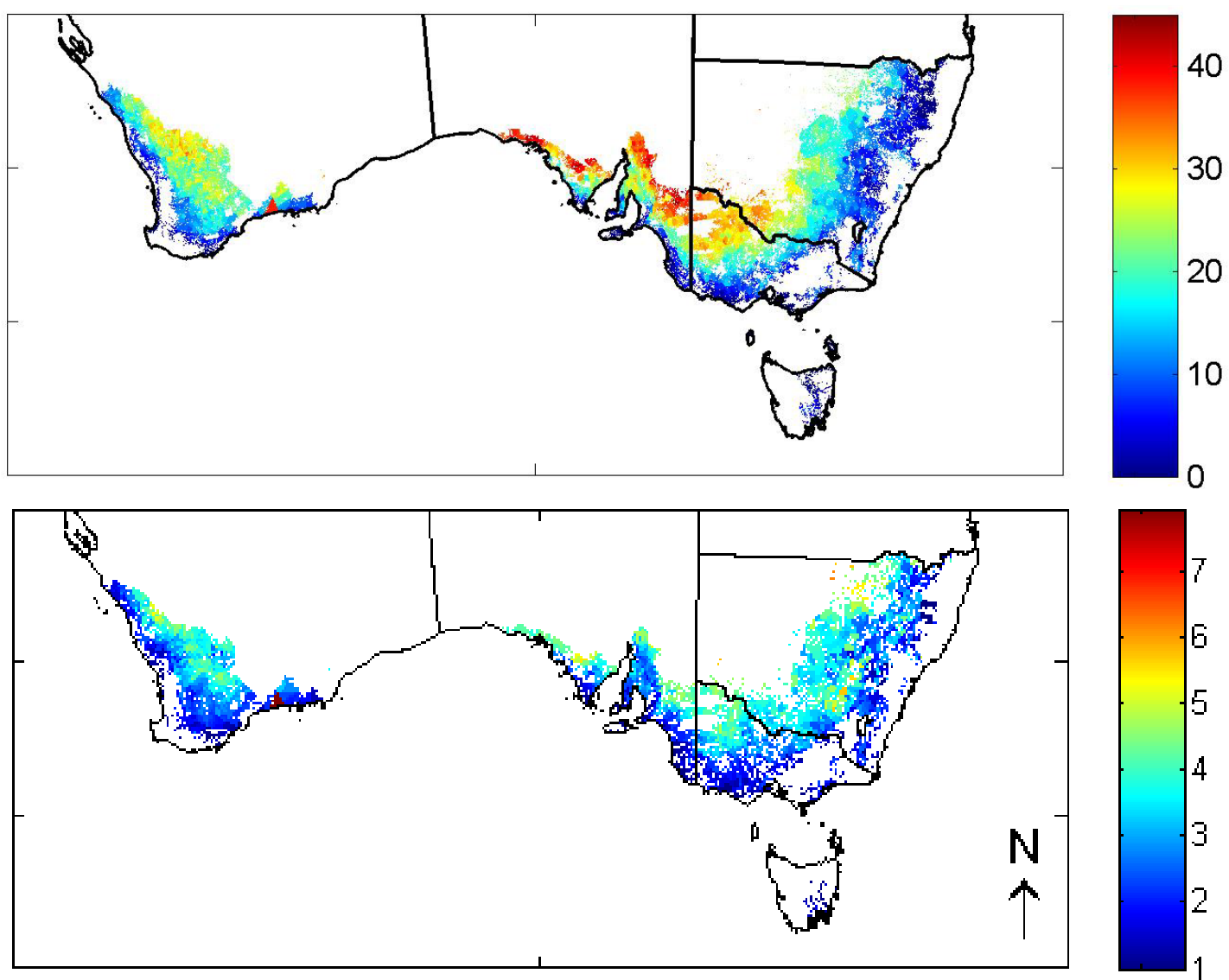

(b)

Figure 4. An analysis of extreme heat days $\left(>35^{\circ} \mathrm{C}\right)$ during grain fill, showing (a) the number of years when extreme heat was recorded, and (b) the average number of extreme heat days in years when they were recorded.

If crops were planted on the autumn break, the results suggest that the occurrence of extreme heat during the grain fill period was common (occurring approximately 2 in 5 years). The area most affected in the study region is considered the traditional wheat belt of Australia (cropping is the major agricultural enterprise) and would represent the region most affected by the increase in extreme temperatures under climate change. Crop models need to adequately account for heat shock given the impact of these extreme temperatures on crop yield. To develop such a crop module, additional experiment work is required, especially in the area of 
Barlow et al., Simulating the impact of extreme heat and frost events on wheat production: the first steps.

threshold temperatures for yield loss, as well as the impacts on grain protein and starch composition as these factors control grain quality, hence actual value of the grain crop.

\section{DISCUSSION AND CONCLUSIONS}

Table 1. Percentage of the study area affected by either extreme heat and/or frost events determined by frequency of occurrence over 50 years.

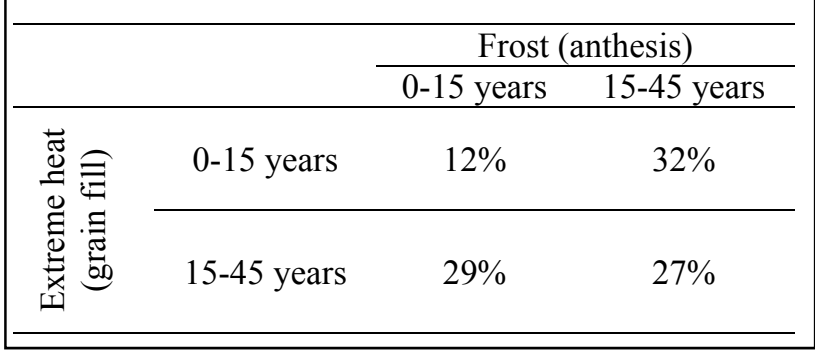

The results presented have shown that both extreme heat during grain fill and frost events around anthesis occurred frequently across the southern Australian cropping regions. We determined that a 1:3 year frequency of event was substantial (approximately 15 years in 50) and grouped our study region (ca. 68 million hectares) according to whether frost and extreme heat occurred more or less frequently (Table 1). Across the study region approximately $27 \%$ (ca. 18.5 million hectares) had a greater than 1:3 chance of both frost and extreme heat occurring at key crop phenological times, while $29 \%$ of the study area was generally affected by heat only during grain fill and $32 \%$ was generally affect by frost only. Additionally $12 \%$ (ca. 8 million hectares) had a less than $1: 3$ frequency of both frost and extreme heat occurring at key crop phenological times.

It is important to acknowledge the sowing time and crop management decisions are more complex than presented in this paper. In some cropping regions delayed planting is used to reduce the risk of frosts around anthesis, which has the potential to expose the crop to higher temperatures during grain fill leading to a 2-3 fold greater loss in potential yield (Fuller et al. 2007). While in other regions, such as the semi-arid regions in north-west Victoria, grower management is weighed towards early sowing of crops to minimise the impact of current dry spring conditions and high temperatures. This balancing act in the management of crops to optimize the planting window highlights the need for models to be able to better inform farm advisors and managers on the risks to yield due to extreme climate conditions.

By incorporating phenological crop development, initiated by the autumn-break, our analysis has established the actual frequency of overlap between extreme events and key phenological stages each year. This approach provides a detailed understanding of the risks of frost and extreme heat in both time and space, compared to the more commonly used approaches which use long term climate data to determine average heat and frost risk periods which are then overlapped with predicted flowering dates.

The extrapolation of extreme climate events across landscapes between climate measuring stations needs additional consideration to provide robust dataset for use by crop models. Whilst extrapolation is the only way of spatially using and analysing climate data, one of the challenges which need to be considered in modelling the impacts of extreme climate events is the magnitude of this effect. Frost as an example is known to be quite variable across the landscape, even at a small spatial scale, with the temperature even across a reasonably level farm varying by up to $4^{\circ} \mathrm{C}$, as cold air is heavy and flows to any hollows in the landscape (Rebbeck and Knell, 2007). This suggests that the application of a frost and potentially an extreme heat model will need to consider the potential implications of spatial variability across the landscape in determining impacts on crop yield at the paddock or regional scale.

\subsection{Conclusion and next steps}

Based on our assumption of planting at the autumn break, the results suggest that the occurrence of frost around anthesis and extreme heat during the grain fill period were considerable both in terms of frequency of occurrence and spatial area affected. A more detailed analysis of extreme heat and frost risk is currently being conducted, which includes multiple planting times as well as short and long-season wheat varieties.

The next step for this research is to develop a conceptual model of extreme heat and frost impacts based on the published literature and a targeted experimental program to fill some knowledge gaps. This will be followed by the development and testing of algorithms using glass house and field data from as broad a range of wheat growing regions as possible. 
Barlow et al., Simulating the impact of extreme heat and frost events on wheat production: the first steps.

\section{ACKNOWLEDGMENTS}

The authors of this paper would like to acknowledge the financial support of the Department of Environment and Primary Industries, Victoria.

\section{REFERENCES}

ABARE, 2012. Australian Crop Report: February 2012. Department of Agriculture, Fisheries and Forestry., Canberra.

Al-Issawi, M., Rihan, H., El-Sarkassy, N., Fuller, M., 2012. Frost hardiness expression and characterisation in wheat at ear emergence. Journal of Agronomy and Crop Science, 1-9.

Alexander, B., Hayman, P., McDonald, G., Talukder, A., Gill, G., 2010. Characterising the risk of heat stress on wheat in South Australia: meteorology, climatology and the design of a field heating chamber., in: Dove, H., Culvenor, R. (Eds.), "Food Security from Sustainable Agriculture" proceedings of 15th Agronomy Conference, Lincoln, New Zealand.

CSIRO, Bureau of Meteorology, 2012. State of the Climate 2012. CSIRO and BoM, p. 12.

DPI, 2009. Models of the Catchment Analysis Tool (CAT1D version 32) August 2009 Future Farming Systems Research, Department of Primary Industries, Rutherglen, Australia.

Ferris, R., Ellis, R.H., Wheeler, T.R., Hadley, P., 1998. Effect of High Temperature Stress at Anthesis on Grain Yield and Biomass of Field-grown Crops of Wheat. Annals of Botany 82, 631-639.

Fuller, M.P., Fuller, A.M., Kaniouras, S., Christophers, J., Fredericks, T., 2007. The freezing characteristics of wheat at ear emergence. European Journal of Agronomy 26, 435-441.

Littleboy, M., Silburn, D.M., Freebairn, D.M., Woodruff, D.R., Hammer, G.L., Leslie, J.K., 1992. Impact of Soil Erosion on Production in Cropping Systems. I. Development and Validation of a Simulation Model. Australian Journal of Soil Research 30, 757-774.

Marcellos, H., Single, W., 1984. Frost Injury in Wheat Ears After Ear Emergence. Functional Plant Biology $11,7-15$.

O’Leary, G., Christy, B., Weeks, A., Nuttall, J., Riffkin, P., Beverly, C., Fitzgerald, G., 2011. Chapter 1.2. Downscaling Global Climatic Predictions to the Regional Level: A Case Study of Regional Effects of Climate Change on Wheat Crop Production in Victoria, Australia., in: Yadav, S., Redden, B., Hatfield, J., Lotze-Campen, H., Hall, A. (Eds.), Crop Adaptation to Climate Change, First ed. John Wiley \& Sons, Ltd, USA, pp. 12-26.

Pradhan, G.P., Prasad, P.V.V., Fritz, A.K., Kirkham, M.B., Gill, B.S., 2012. Effects of drought and high temperature stress on synthetic hexaploid wheat. Functional Plant Biology 39, 190-198.

Rebbeck, M., Knell, G., 2007. Managing frost risk: a guide for southern Australian grains., in: Reuter, D. (Ed.). South Australian Research and Development Institure and Grains Research and Development Corporation, Canberra, Australia.

Stone, P., Nicolas, M., 1995. A survey of the effects of high temperature during grain filling on yield and quality of 75 wheat cultivars. Australian Journal of Agricultural Research 46, 475-492.

Talukder, A., Gill, G., McDonald, G., Hayman, P., Alexander, B., 2010. Field evaluation of the sensitivity of wheat to high temperature stress near flowering and early grain set., in: Dove, H., Culvenor, R. (Eds.), Food Security from Sustainable Agriculture. . 15th Agronomy Conference, Lincoln, New Zealand.

Wardlaw, I., Wrigley, C., 1994. Heat Tolerance in Temperate Cereals: an Overview. Functional Plant Biology 21, 695-703.

Weeks, A., Christy, B., Lowell, K., Beverly, C., 2008. The Catchment Analysis Tool: demonstrating the benefits of interconnected biophysical models., in: Pettit, C., Cartwright, W., Bishop, I., Lowell, K., Pullar, D., Duncan, D. (Eds.), Landscape Analysis and Visualisation. Springer-Verlag, Berlin, pp. 49-71.

Williams, J.R., Jones, C.A., Kiniry, J.R., Spanel, D.A., 1989. The EPIC Crop Growth Model. Transactions of the American Society of Agricultural and Biological Engineers 32, 497-511. 